\title{
Default by intervention: Allomorphy and locality in the Modern Greek verb
}

\author{
Lefteris Paparounas*
}

\begin{abstract}
An often discussed dimension of the locality conditions on allomorphy is visibility: when do the trigger and target of allomorphy 'see' each other? An equally important dimension is intervention: when do the trigger and target stop seeing each other? This paper offers two case studies on intervention from Modern Greek verbal morphology. In Greek, Agr is sensitive to the features of Voice, and T is sometimes sensitive to the identity of the root; but in both cases, allomorphy only takes place when all heads intervening between the target and trigger are null. When at least one intervening head is overt, the target retreats to a default realization. I argue that such patterns, whereby intervention leads to the emergence of a default, are readily understandable in theories where adjacency of heads is a necessary condition for allomorphy, and where only null nodes may be transparent.
\end{abstract}

Keywords. morphology; morphophonology; allomorphy; spanning; Modern Greek

1. Introduction. A long-standing question in morphological theory concerns the domain restrictions on contextual allomorphy (e.g. Allen 1979; Siegel 1978): how local must the trigger of allomorphy be to the target, and what kinds of representations is locality computed over?

Within Distributed Morphology (Halle \& Marantz 1993 et seq.), this general question has given rise to a number of more specific debatess, one of which concerns the role of adjacency. Theories that treat heads as the targets of Vocabulary Insertion often posit that adjacency of heads, either linear (e.g. Embick 2010; Ostrove 2018) or structural (e.g. Adger et al. 2003; cf. Bobaljik:2012) is a necessary condition for allomorphy. By contrast, theories that take insertion to operate over non-head objects, such as spans (Svenonius 2012; Merchant 2015), naturally eschew reference to head adjacency.

Argumentation in this domain often begins from considerations of visibility. In particular, arguments for or against particular locality conditions on allomorphy often take the form 'insertion at target $\mathrm{X}$ is apparently conditioned by trigger $\mathrm{Y}$; therefore our theories must countenance interactions within the minimal domain that includes X and Y' (e.g. Merchant 2015; Ganenkov 2020). But an equally important dimension involves intervention, whereby $\mathrm{X}$ and $\mathrm{Y}$, which normally interact, cease to do so when a third element $\mathrm{Z}$ intervenes between them.

This paper offers two case studies on morphological intervention from Modern Greek verbal morphology. Both illustrate what I call default by intervention: a specific Vocabulary Item loses the competition to a more general one because the context for insertion of the more specific exponent is present in the structure, but inaccessible. I argue that such patterns follow naturally under adjacency-based theories of insertion, but seem mysterious under less restrictive theories such as spanning.

2. Background on Greek verbs. The Greek verbal system is structured around three binary oppositions, in Voice (active verus non-active), Aspect (perfective versus imperfective) and Tense (past versus non-past). Table 1 illustrates with the first-singular forms of the verb 'write', seg-

\footnotetext{
* For helpful discussion and comments, I thank Johanna Benz, David Embick, Laura Kalin, Alex Kalomoiros, Julie Anne Legate, Rolf Noyer, Roberto Petrosino, and the audience at the $95^{\text {th }}$ Annual Meeting of the LSA. All errors are my own. Authors: Lefteris Paparounas, University of Pennsylvania (lefteris@sas.upenn.edu).
} 
mented to reflect the decomposition argued for in this paper (cf. Joseph \& Smirniotopoulos 1993; Galani 2005; Petrosino \& Christopoulos 2018; Merchant 2015).

\begin{tabular}{|c|c|}
\hline ACT.IMPF.NONPST & ACT.PFV.NONPST \\
\hline yràf- $\quad 0$ & fràf- $\quad s-\quad o$ \\
\hline$\sqrt{\text { WRITE }}$ AGR & $\sqrt{\text { WRITE }}$ ASP AGR \\
\hline NONACT.IMPF.NONPST & NONACT.PFV.NONPST \\
\hline yràf- ome & yraf- $\theta-$ ò \\
\hline$\sqrt{\text { WRITE AGR }}$ & $\sqrt{\text { WRITE ASP AGR }}$ \\
\hline ACT.IMPF.PST & ACT.PFV.PST \\
\hline è- yraf- a & è- yraf- s- a \\
\hline TNS $\sqrt{\text { WRITE AGR }}$ & TNS $\sqrt{\text { WRITE ASP AGR }}$ \\
\hline NONACT.IMPF.PST & NONACT.PFV.PST \\
\hline yraf- òmun & yràf- $\quad \theta^{1}-\mathrm{ik}-\mathrm{a}$ \\
\hline$\sqrt{\text { WRITE }}$ AGR & $\sqrt{\text { WRITE }}$ ASP TNS AGR \\
\hline
\end{tabular}

Table 1. First-singular forms of yrafo 'write'

A few introductory notes on the segmentation are in order. Firstly, it can be seen that the form of Agr varies depending on the features on Voice: one set of agreement endings $(-o$ and $-a)$ appears in active forms, another (--ome and --òmun) in some nonactive forms. Secondly, [PST] can be realized either as a prefixal $e$-, known as the augment, or as a suffix $-i k$. The realization of Agr and T will form the basis of the discussion in Sections 3 and 4, respectively.

Moreover, crucial in what follows will be the realization of Asp. Though imperfective Asp is always zero in the language ${ }^{2}$, perfective Asp is realized with two exponents. Its default realization is with the suffix $-s$, which appears in the active forms. In the nonactive, $-s$ loses to the more specific exponent $-\theta$, which is the realization of perfective Asp in the context of nonactive Voice. The Vocabulary Items in (1) summarize.

\section{(1) VIs for Voice and Asp}
a. $\quad[\text { NONACT }]_{\text {Voice }} \leftrightarrow \emptyset$
b. $[-\mathrm{PFV}]_{\text {Asp }} \leftrightarrow \varnothing$
c. $[+ \text { PFV }]_{\text {Asp }} \leftrightarrow / \theta / /[\text { NONACT }]_{\text {Voice }}$
d. $[+\mathrm{PFV}]_{\text {Asp }} \leftrightarrow / \mathrm{s} /$

The treatment of $/ \theta /$ defended here differs from previous accounts, which assume that this exponent realizes non-active Voice in the context of perfective Asp (Rivero 1990; Merchant 2015; Spyropoulos \& Revithiadou 2009; Manzini et al. 2016). Though plausible at first glance, such

\footnotetext{
${ }^{1}$ A regular phonological process of manner dissimilation changes $/ \theta /$ to $[t]$ after fricatives, thus forms like this end up as [yraf-t-ik-a]. I 'undo' this process and notate the affix as $/ \theta /$ throughout this paper for the reader's convenience.

${ }^{2}$ This fact may well motivate a privative treatment of Asp, whereby this head is only present in the perfective. Nothing depends on this in what follows.
} 
a treatment would miss an important fact, namely, that $/ \theta /$ and $/ \mathrm{s} /$ are in complementary distribution throughout the verbal system: no nonactive perfective form shows both $/ \theta /$ and $/ \mathrm{s} /{ }^{3}$. That /s/ realizes perfective Asp is in turn evident from its presence in the perfective, but not imperfective, active forms as in Table 1 . To the extent that $/ \mathrm{s} /$ has not always been recognized in previous analyses, this may be due to the fact that it is regularly lost with sonorant-final roots (e.g. stel-n'send.ACT.IMPF' versus stil-(*s-) 'send.ACT.PFV').

I take the input to PF to be as in (2). Here, [NONACT] is a feature assigned postsyntactically to syntactic configurations lacking an external argument (Embick 1998); Asp and T bear binary $[\mathrm{PFV}]$ and $[\mathrm{PST}]$ features, respectively; and Agr is a dissociated morpheme hosting person and number features.

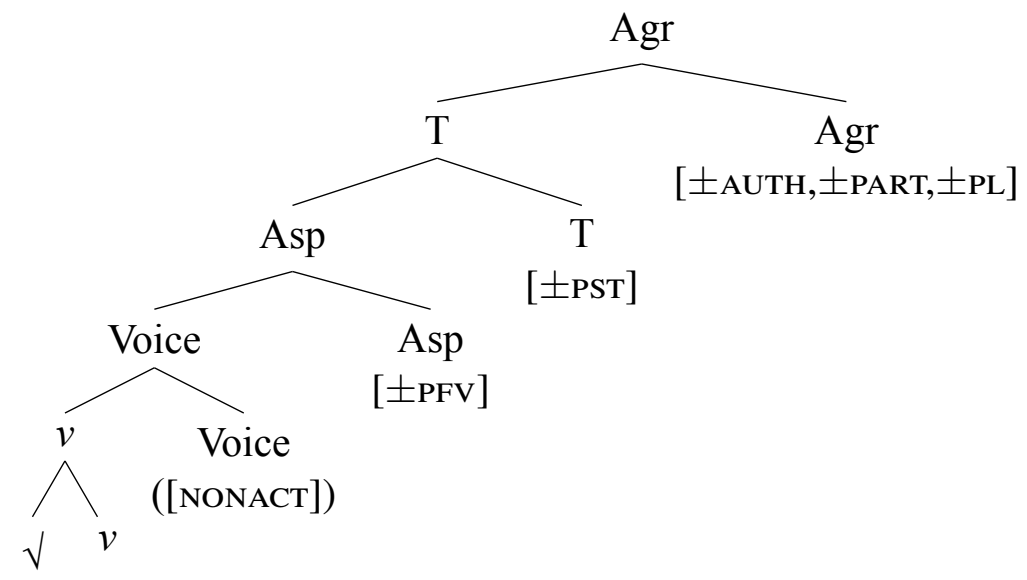

3. Case study 1: Voice allomorphy. The role of intervention in insertion can be illustrated firstly with reference to the interaction between Voice and Agr. As mentioned above, the realization of Agr in Greek is conditioned by the features on Voice. Descriptively, Agr can take the set of 'active' endings ( $-o$ in the non-past, and $-a$ in the past), or the set of non-active endings (-ome in the non-past, and -omun in the past).

Interestingly, however, the distribution of the two sets of endings is asymmetric, as shown in Table 2. The left column shows that, in the imperfective, the expected distribution is found: 'active' agreement endings (shaded with light gray) in the active forms, and non-active ones (shaded with dark gray) in the non-active forms. But in the perfective, the 'active' agreement endings are found throughout; the non-active endings do not appear in the non-active perfective forms (Joseph \& Smirniotopoulos 1993; Leu 2020). We thus find yraf- $\theta-o$ instead of expected * $r r a f-$ $\theta$-òme, and yràf- $\theta$-ik- $a$ instead of expected * $r a f-\theta$-ik-òmun. The VIs inserting the non-active endings apparently 'underapply'; why is the distribution asymmetric in this way?

There is a striking generalization evident in Table 2: Agr is only realized with the non-active endings when all heads between Agr and Voice are null. This is the case in the imperfective forms, but not in the perfective forms, where $\mathrm{T}$ and/or Asp are overt. This is intervention at work: the trigger of allomorphy, Voice, ceases to be visible to the target, Agr, when overt exponents intervene between the two. To derive this generalization, I will make use of three ingredients.

\footnotetext{
${ }^{3}$ Note further that apparent Mirror Principle-violating co-occurrence of these exponents is illusory: in forms like klis- $\theta$ - 'close.NONACT.PFV', the /s/ is part of the root, as evidenced by its presence in the participles klis-to-s and klis-men-os 'closed' (compare the participle of 'write' graf-to-s, * $\mathrm{rrafs-tos}$ ).
} 


\begin{tabular}{|c|c|}
\hline $\begin{array}{l}\text { ACT.IMPF.NONPST } \\
\text { yràf- O } \\
\sqrt{\text { WRITE AGR }}\end{array}$ & $\begin{array}{l}\text { ACT.PFV.NONPST } \\
\text { yràf- s- o } \\
\sqrt{\text { WRITE ASP AGR }}\end{array}$ \\
\hline $\begin{array}{c}\text { NONACT.IMPF.NONPST } \\
\text { yràf- Ome } \\
\sqrt{\text { WRITE AGR }}\end{array}$ & $\begin{array}{l}\text { NONACT.PFV.NONPST } \\
\text { yraf- } \theta \text { - ò } \\
\sqrt{\text { WRITE ASP AGR }}\end{array}$ \\
\hline $\begin{array}{l}\text { ACT.IMPF.PST } \\
\text { è- yraf- a } \\
\text { TNS } \sqrt{\text { WRITE }} \text { AGR }\end{array}$ & $\begin{array}{l}\text { ACT.PFV.PST } \\
\text { è- } \text { yraf- s- } \text { a } \\
\text { TNS } \sqrt{\text { WRITE }} \text { ASP AGR }\end{array}$ \\
\hline $\begin{array}{c}\text { NONACT.IMPF.PST } \\
\text { yraf- òmun } \\
\sqrt{\text { WRITE AGR }}\end{array}$ & $\begin{array}{l}\text { NONACT.PFV.PST } \\
\text { fràf- } \theta-i k-\text { a } \\
\sqrt{\text { WRITE ASP TNS AGR }}\end{array}$ \\
\hline
\end{tabular}

Table 2. 'Active' and non-active Agr in the 1sg forms of 'write'

Firstly, it is necessary to set up the appropriate Vocabulary. Although the non-active agreement endings are true contextual realizations of Agr sensitive to the features of Voice, I will take it that the so-called 'active' endings are in fact default realizations of Agr, with the VIs inserting them making no reference to Voice.

(3) VIs for Agr

a. $[+ \text { AUTH },+ \text { PART, }- \text { PL }]_{\mathrm{Agr}} \leftrightarrow /$ omun/ $/[\text { NONACT }]_{\mathrm{Voice}}[+\mathrm{PST}]_{\mathrm{T}}$

b. $[+ \text { AUTH, }+ \text { PART, -PL }]_{\text {Agr }} \leftrightarrow /$ ome $/ /[\text { NONACT }]_{\text {Voice }}$

c. $[+ \text { AUTH },+ \text { PART, }- \text { PL }]_{\text {Agr }} \leftrightarrow / \mathrm{a} / /[+ \text { PST }]_{\mathrm{T}}$

d. $[+ \text { AUTH, }+ \text { PART, }- \text { PL }]_{\text {Agr }} \leftrightarrow / \mathrm{o} /$

The second ingredient of my analysis of this intervention pattern is an adjacency-based theory of insertion. For concreteness, I adopt the linear adjacency-based model of (Embick 2010); in principle, the analysis could also be made compatible with the assumptions of structural adjacencybased theories (see footnote 4). I will thus assume that a hierarchical structure of the kind in (4) is linearized into the statement in (5). (5) expresses a set of pairwise concatenation relationships: the root is concatenated with $\mathrm{X}, \mathrm{X}$ with $\mathrm{Y}$, and so on. (5) is the representation over which insertion takes place, constrained by (6). This guarantees that, all things being equal, in (5), the root can only be conditioned by X, X can only be conditioned by the root and Y, and so on.

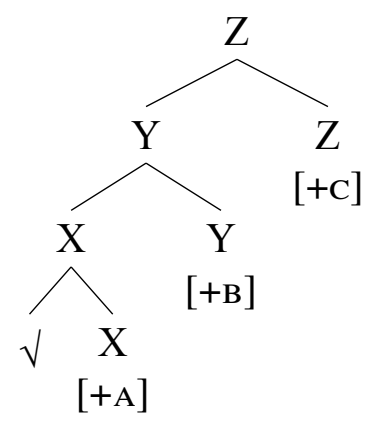

(5) $\sqrt{ }-\mathrm{X}_{[+\mathrm{A}]}, \mathrm{X}_{[+\mathrm{A}]} \sim \mathrm{Y}_{[+\mathrm{B}]}, \mathrm{Y}_{[+\mathrm{B}]} \sim \mathrm{Z}_{[+\mathrm{c}]}$

(6) Node Adjacency Hypothesis

Allomorphy is only possible with elements that are concatenated.

(Embick 2010, 2012) 
Unless augmented with an additional ingredient, (6) is too strong, effectively barring all long-distance interactions. The third ingredient required, then, is a device that effectively renders null nodes transparent for allomorphy, guaranteeing that long-distance allomorphy is possible only across a null head. This is the role of the mechanism of Pruning in Embick (2010): Pruning removes null nodes from the linearization statement, and its application triggers re-concatenation, such that two nodes that were previously separated by a null head are now adjacent. To illustrate Pruning, consider (7), where (5) has undergone insertion up to Y: the root has been realized as some exponent $/ \pi /$, X has received an exponent $/ \alpha /$, and $\mathrm{Y}$ is null. Pruning of $\mathrm{Y}$ is illustrated in (8): $\mathrm{Y}$ is removed from the structure, and $\mathrm{Z}$ and $\mathrm{X}$ become adjacent.

$$
\begin{aligned}
& V_{/ \pi /} \frown \mathrm{X}_{[+\mathrm{A}] / \alpha /}, \mathrm{X}_{[+\mathrm{A}] / \alpha /} \sim \mathrm{Y}_{[+\mathrm{B}] / \varnothing /,}, \mathrm{Y}_{[+\mathrm{B}] / \varnothing /} \sim \mathrm{Z}_{[+\mathrm{C}]} \\
& \mathrm{X}[\alpha]^{\frown} \mathrm{Y}[\varnothing], \mathrm{Y}[\varnothing] \frown \mathrm{Z} \rightarrow \mathrm{X}[\alpha] \frown \mathrm{Z}
\end{aligned}
$$

An important question here concerns which zeroes are transparent. In a Pruning-based treatment, this question effectively translates into a need to specify the conditions under which Pruning applies. I will tentatively take it that Pruning is a last resort operation, triggered just in case there exists a VI which demands access to more than one node, as in (9) (a hyper-contextual VI, in the terms of Moskal \& Smith 2016). Whether this approaches a correct statement of the conditions on Pruning on a more general level is a question I leave open. ${ }^{4}$

$$
[+\mathrm{c}]_{\mathrm{Z}} \leftrightarrow / \beta / /[]_{\mathrm{X}}[]_{\mathrm{Y}}
$$

With these ingredients in place, we are now in a position to derive the asymmetric distribution of agreement endings noted above. I illustrate here with trees for the purposes of readability. First, consider the derivation of a nonactive perfective past form such as $y r a f-\theta-i k-a$ in Table 1.

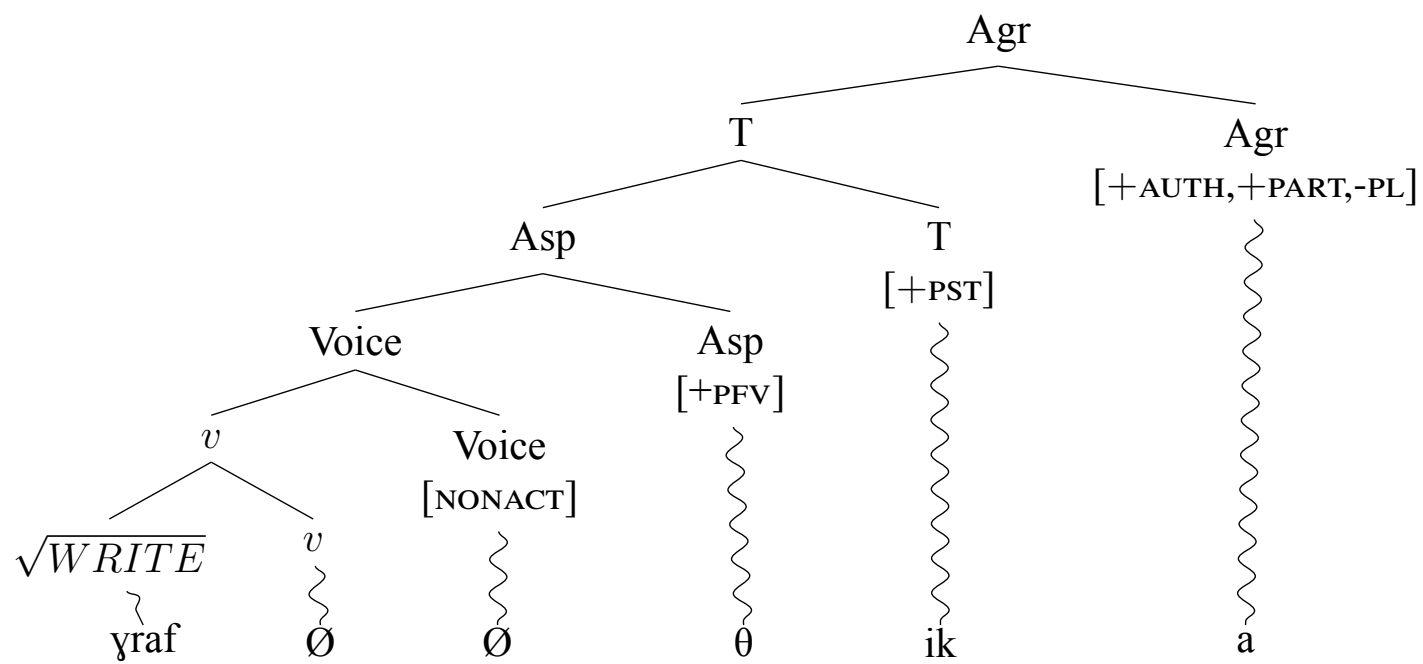

Assume that insertion proceeds from the root outwards following (Bobaljik 2000), and con-

\footnotetext{
${ }^{4}$ Whether the analysis offered here is fully compatible with structural adjacency depends to some extent on what the equivalent of Pruning would be in a theory with structural adjacency. It also seems that the specific notion of structural adjacency would itself have to be made precise: assuming a representation like (4), simple sisterhood will likely not give the correct result, given that, say, the sister of $\mathrm{Z}$ is not $\mathrm{Y}$ itself but rather a projection of $\mathrm{Y}$ that also contains $\mathrm{X}$ and the root. I lack the space necessary to spell out the details for the Greek case studies here.
} 
sider the stage of (10) where every node but Agr has undergone insertion. Of the candidate VIs in (3), (3-a) and (3-b) demand access to Voice. These hyper-contextual VIs will trigger Pruning, but Pruning cannot apply; Agr is concatenated with T, which has been overtly realized as $-i k$. The context for (3-a) and (3-b) thus cannot be satisfied; the insertion mechanism will default to a more general VI, in this case, (3-c), which demands reference to [+PST]. This VI will apply, correctly inserting the 'active' exponent $-a$. In the corresponding nonpast form of Table 1, zraf- $\theta-o$, $\mathrm{T}$ can undergo Pruning but the overt exponent of Asp will intervene, again forcing Agr to retreat to a default realization.

By contrast, in an imperfective form such as nonactive imperfective past yraf-òmun in (11) below, no exponent will intervene between Agr and Voice. Asp and T, both null, will undergo Pruning, schematized here with a delink symbol; with Voice and Agr becoming adjacent, the most specific VI (3-a) will apply.

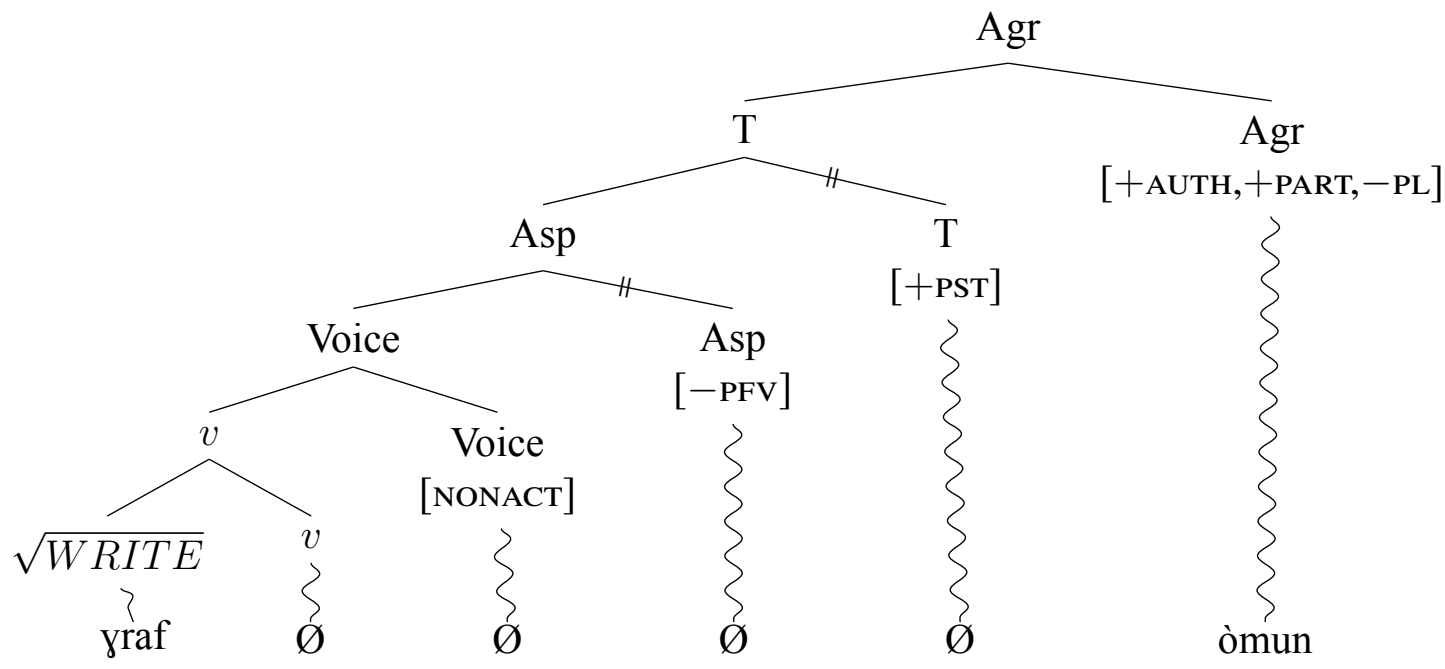

4. Case Study 2: Exponence of [+PST]. The standard realization of [+PST] in Greek is the prefixal $e$ - that normally appears in active past forms, known as the augment. It is well known that the appearance of the augment is sensitive to prosodic conditions: specifically, the augment seems to appear whenever a [+PST] form does not supply a syllable to host antepenultimate stress (Kaisse 1982; Galani 2005; van Oostendorp 2012; Spyropoulos \& Revithiadou 2009). This prosodic sensitivity can be illustrated by comparing the shape of past forms of monosyllabic and disyllabic roots. A monosyllabic root like yraf- 'write' obligatorily surfaces with the augment in the past, as in (12-a). But the past of a disyllabic root like djavaz- 'read' is unaugmented: here, the combination of disyllabic root and syllabic affix ensures that an antepenult is already supplied, and the augment does not surface. ${ }^{5}$ Further illustration of the neatness of this distribution is provided by the paradigm of the active past perfective forms of yraf- in (13). In the singular, the agreement affixes are monosyllabic and, since the root is also monosyllabic, the augment is inserted to host antepenultimate stress; in the first and second plural, insertion of the disyllabic agreement endings obviates augment insertion. In the third plural, the agreement affix may or may not be

${ }^{5}$ This is so for standard Modern Greek; in more conservative varieties, such as Cretan and Cypriot, the augment's distribution is not as intimately tied to antepenultimate stress. See Pavlou (2017) for Cypriot Greek. 
monosyllabic; if the monosyllabic variant is chosen, the augment is inserted, while the disyllabic variant bleeds augmentation.

$$
\begin{aligned}
& \text { a. è- } \text { yraf- a, } \text {, *yràf-a } \\
& \text { PST- } \sqrt{\text { WRITE}}-1 \text { sG.PST } \\
& \text { b. }{ }^{*} \text { - } \text { ðjavaz- a djàvaz-a } \\
& \text { PST- } \sqrt{\text { READ- }} \text { 1sG.PST }
\end{aligned}
$$

\begin{tabular}{lc}
\hline \hline & ACT.PST.PFV \\
\hline 1 SG & è-yraf-a \\
2 SG & è-yraf-es \\
3 SG & è-yraf-e \\
1 PL & yràf-ame \\
2 PL & yràf-ate \\
3 PL & è-yraf-an / yràf-ane \\
\hline \hline
\end{tabular}

It is thus possible to relegate the conditions for the appearance of the augment entirely to morphophonology (Kaisse 1982): under such an approach, whenever we do not find the augment in a [+PST] form, as in the nonactive forms of Table 3, it is because the prosodic shape of the root and its affixes removes the conditions for augment insertion. The complementary distribution of the augment and $-i k$ can also be derived from the former's prosodic conditioning: for example, in Merchant (2015), -ik is taken to realize Asp, and, by being syllabic, its addition to a root (along with the agreement affix) bleeds insertion of the augment.

\begin{tabular}{cl}
\hline \hline ACT.IMPF.PST & \multicolumn{1}{c}{ ACT.PFV.PST } \\
è - yraf- a & è - rraf- s- a \\
TNS $\sqrt{\text { WRITE AGR }}$ & TNS $\sqrt{\text { WRITE ASP AGR }}$ \\
& \\
NONACT.IMPF.PST & NONACT.PFV.PST \\
yraf- òmun & yràf- $\theta-$ ik- a \\
$\sqrt{\text { WRITE AGR }}$ & $\sqrt{\text { WRITE ASP TNS AGR }}$ \\
\hline
\end{tabular}

Table 3. First-singular forms of yrafo 'write'

But an interesting complication for this simple approach arises with a handful of roots, exemplified by 'find' in Table 4 (compare Table 3, and cf. Spyropoulos \& Revithiadou 2009). The issue arises in the active perfective past form, which is an unaugmented disyllabic form. This is unexpected given the augment's prosodic conditioning just discussed: given the above, we would expect $* \grave{e}-v r-i k-a$ (in fact the attested Classical Greek form), contrary to fact.

\begin{tabular}{cc}
\hline \hline ACT.IMPF.PST & ACT.PFV.PST \\
è -vrisk-a & vr-ìk-a \\
& \\
NONACT.IMPF.PST & NONACT.PFV.PST \\
vrisk-òmun & vre- $\theta$-ik-a \\
\hline \hline
\end{tabular}

Table 4. Past forms of 'find' 
The issue is not confined to this root: as shown in Table 5. $\sqrt{\text { ENTER }}$ and $\sqrt{\text { EXIT }}$ are like $\sqrt{\text { FIND }}$ in taking -ik in the unexpectedly unaugmented active perfective past form; $\sqrt{\text { TAKE }}$ and $\sqrt{\text { GO }}$ instead take a null exponent, but still form augment-less disyllabic past forms.

\begin{tabular}{cccc}
\hline \hline ACT.IMPF.NONPST & ACT.IMPF.PST & ACT.PFV.PST & Gloss \\
vr-isk-o & è-vr-isk-a & vr-ìk-a & 'find' \\
b-en-o & è-b-en-a & b-ìk-a & 'enter' \\
vj-en-o & è-vj-en-a & vj-ìk-a & 'exit' \\
per-n-o & è-per-n-a & pìr-Ø-a & 'take' \\
pij-en-o & pìj-en-a & pì̀-Ø-a & 'go' \\
\hline \hline
\end{tabular}

Table 5. Special [+PST] exponents in the active perfective

It is thus not the case that the augment freely appears whenever a [+PST] form lacks an antepenult. Instead, as the perfective past forms of Table 5 illustrate, we need a layer of morphological competition that may obviate the insertion of the augment altogether. To account for the relevant verbs, then, we may posit two more allomorphs of T, as in (14). One will insert -ik with the relevant set of roots; another will insert a null allomorph of $\mathrm{T}$ with a disjoint set of roots. Importantly, these two VIs compete with the default realization of T, namely the VI inserting the null allomorph $/ \varnothing^{*} /$.

\section{Some VIs for T}

a. $\left[+{ }^{\mathrm{PST}}\right]_{\mathrm{T}} \leftrightarrow / \mathrm{ik} / /\{\sqrt{\mathrm{FIND}}, \sqrt{\text { ENTER }}, \sqrt{\mathrm{EXIT}}\}$

b. $[+ \text { PST }]_{\mathrm{T}} \leftrightarrow / \varnothing / /\{\sqrt{\mathrm{TAKE}}, \sqrt{\mathrm{GO}}\}$

c. $[+\mathrm{PST}]_{\mathrm{T}} \leftrightarrow / \varnothing^{*} /$

I take (14-c) to be the allomorph that triggers prefixation of the augment. * is here intended as a diacritic to this end: the null allomorph in (14-c) causes the form's prosodic profile to be evaluated in the morphophonology, after insertion has been completed. If the form has an antepenult, no operation occurs; but if the form lacks an antepenult, * triggers prefixation of $e$ - to host stress. The details of this morphophonological process are not central here; see Spyropoulos \& Revithiadou (2009) for one proposal. ${ }^{6}$

The important aspect of (14) is that, whenever (14-a) or (14-b) applies, (14-c), the augmenttriggering VI, has lost the competition. In other words, (14-a) and (14-b) will bleed insertion of the augment, because choosing one of these VIs entails not choosing the allomorph capable of inserting the augment.

Note now that, although (14) is necessary to account for the perfective past forms of Table 5, it is not sufficient to account for other forms of this table. The issue we face is that the distribution of the 'special' $T$ exponents (-ik or $\varnothing)$ is once again asymmetrical: these exponents surface in the active perfective, giving forms like $v r-i k$ - $a$, but do not surface in the active imperfective.

\footnotetext{
${ }^{6}$ The careful reader may wonder why I have not taken (14-c) to insert $e$ - at T directly, perhaps accompanied by linearization of $\mathrm{T}$ to the left. The reasons for this are twofold. Such a solution would not be compatible with serial inside-out insertion, assumed here. Recall that we want $e$ - to surface only when the form will lack an antepenult; but, at the point where insertion targets $\mathrm{T}$, this information on the eventual prosodic shape of the form is not yet available, because Agr has not been targeted for insertion yet. ]
} 
Given (14-a) and (14-b), we might expect the imperfective past of these roots to form forms like *vr-isk-ik-a, but in fact we find the augment surfacing instead, giving e.g. $\dot{e}$-vr-isk-a.

As in the case of Voice allomorphy discussed in the previous section, the specific VI ostensibly underapplies: though the roots which form the context for (14-a) and (14-b) are clearly present in both the imperfective and the perfective past forms of Table 5, they only seem to successfully condition allomorphy of $\mathrm{T}$ in the perfective. Why, then, is root-sensitive allomorphy only found in the perfective?

I argue that intervention is once again the culprit here. To see why, consider a striking generalization on the relevant verbs, summarized in 6 below: these verbs all bear overt verbalizers (see Spyropoulos et al. 2015), but only in the imperfective. In the perfective, $v$ is always null.

\begin{tabular}{|c|c|c|}
\hline ACT.IMPF.NONPST & ACT.PFV.NONPST & Gloss \\
\hline vr- isk- o & vr- & 'find' \\
\hline$\sqrt{\text { FIND }}$ VBZ AGR & $\sqrt{\text { FIND }}$ VBZ AGR & \\
\hline$b-\quad$ en- o & Ø- 0 & 'onter' \\
\hline$\sqrt{\text { ENTER }}$ VBZ AGR & $\sqrt{\text { FIND }}$ VBZ AGR & emel \\
\hline vj- en- o & $\varnothing-0$ & 'oxit' \\
\hline$\sqrt{\text { EXIT }}$ VBZ AGR & $\sqrt{\text { EXIT }}$ VBZ AGR & \\
\hline per- $\quad \mathbf{n}-\quad$ o & par- Ø- o & 'take' \\
\hline$\sqrt{\text { TAKE }}$ VBZ AGR & $\sqrt{\text { TAKE }}$ VBZ AGR & \\
\hline pij- en- $o^{7}$ & pa- Ø- о & ' 'oQ' \\
\hline$\sqrt{\mathrm{GO}}$ VBZ AGR & $\sqrt{\mathrm{GO}}$ VBZ AGR & \\
\hline
\end{tabular}

Table 6. Overt and null verbalizers and aspect

This generalization on the overtness of $v$ is crucially relevant to the way in which the VIs in (14) will apply. Recall that the more specific VIs, (14-a) and (14-b), demand access to the root. Under the assumptions outlined in the previous section, $\mathrm{T}$ will only be able to access the root if all intervening heads are null. For the relevant verbs, this may be possible in the perfective, where $v$, the node adjacent to the root, is null; but in the imperfective, overt $v$ will close off the root, forcing $\mathrm{T}$ to be realized with a default allomorph (see Petrosino \& Christopoulos 2018 for a related observation).

As an illustration, consider first the derivation of a past imperfective form like $\grave{e}$ - $v r$-isk-a 'I was finding' in (15) below. For insertion at T, VI (14-a) will be evaluated; this Vi demands access to the root, so Asp and Voice, both null, will undergo Pruning. But this attempt to make $\mathrm{T}$ local to the root will fail, because $v$, the last barrier, is overt and intervenes. $T$ and the root thus cannot be made adjacent, and T defaults to the elsewhere VI (14-c). The augment-triggering / $\varnothing^{* /}$

${ }^{7}$ For some speakers, including myself, the active imperfective nonpast of $\sqrt{\mathrm{GO}}$ has an unverbalized variant $p a-o$, homophonous with the corresponding perfective form. This is orthogonal to the point made here on the realization of [+PST] T since, even for these speakers, the past imperfective form is always overtly verbalized. 
will thus be inserted and, in this case, lead to prefixation of $e$ - in the morphophonology, given that the output of insertion is a disyllabic past form that bears *.

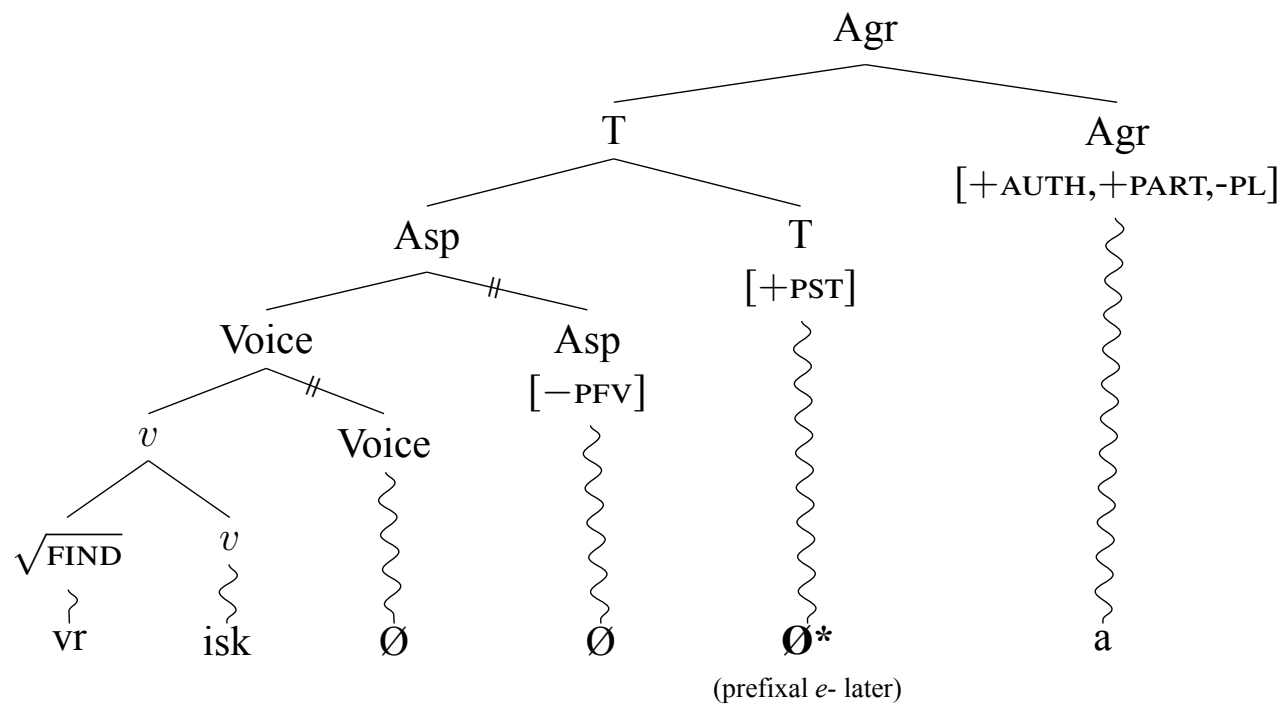

Now consider the derivation of the corresponding perfective form $v r-i k$ - $a$ 'I found' in (16). The crucial difference is that, in this case, $v$ is null - Pruning of all intervening nodes will thus make $\mathrm{T}$ adjacent to the root. The context of (14-a) is now met, and the more specific exponent $-i k$ is inserted. Note that, because the augment-triggering (14-c) has lost the competition, augmentation will not be triggered, yielding an unaugmented disyllabic past form.

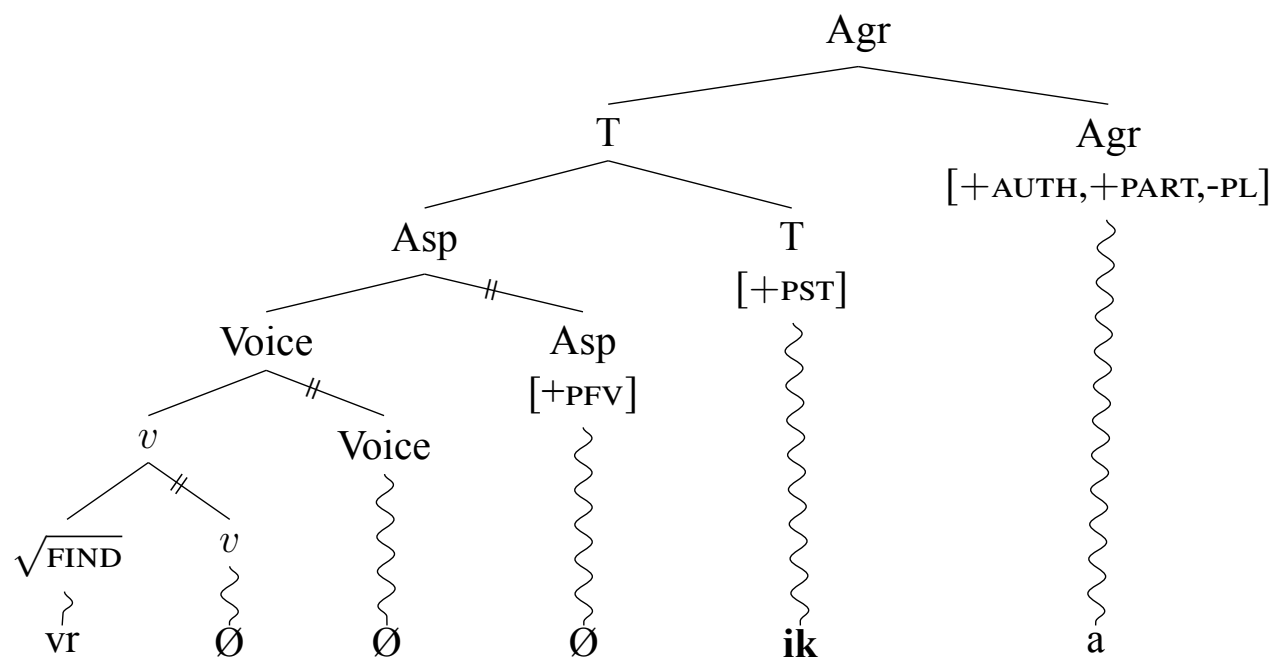

5. General discussion. Both case studies discussed in this paper illustrate default by intervention. Agr co-varies with Voice only when all intervening heads are null, and similarly for T and the root. In both cases, a default VI wins over a more specific one whenever the latter's context is inaccessible. 
I have shown how such patterns of intervention follow in theories making crucial reference to head adjacency, with a special role afforded to null nodes. If adjacency is a necessary condition for contextual realization, and only null nodes can be made to be 'out of the way' for the purposes of a given context, then situations where a head loses its ability to co-vary with a distant trigger when intervening heads are overt are precisely what we expect to find.

5.1. Intervention AND SPANning. An important question, then, concerns how such patterns should be accommodated in theories that eschew head adjacency. As this broad characterization subsumes a number of distinct approaches, here I focus specifically on spanning (Svenonius 2012; Bye \& Svenonius 2012; Merchant 2015), where the targets and contexts of insertion are taken to be sets of contiguous nodes called spans.

For the Greek case studies, it is clear that a spanning approach would face no difficulty with generating the relevant forms. For example, the analysis of the Greek system in Merchant (2015) takes the non-active endings to realize the span <Voice Asp T Agr $>$ (17), effectively treating them as large portmanteaux (cf. Joseph \& Smirniotopoulos 1993); the active endings then realize a smaller span, <T Agr $>$ (18).

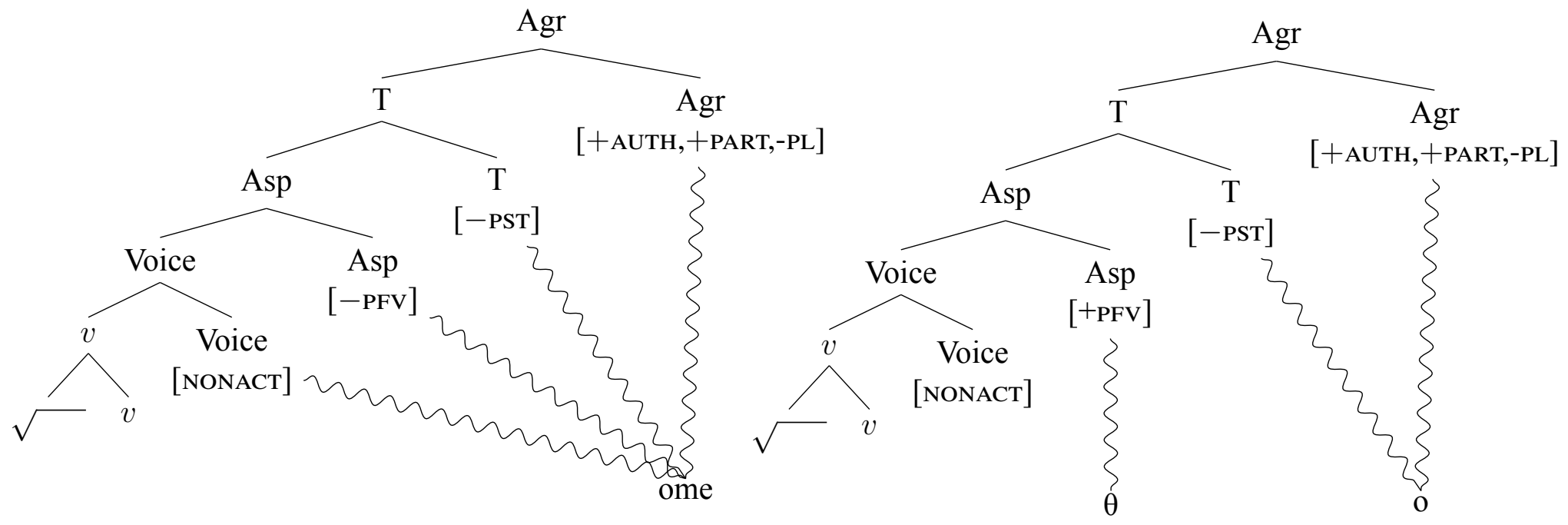

But it seems far from clear that such an approach leads to a principled treatment of the intervention patterns. The latter seem mysterious: the agreement ending happens to realize the smaller span just when a different (trivial) span, Asp, is realized overtly. But the overtness of an adjacent span (much less an adjacent head) does not have any status in this theory; even if the non-active ending in (17) were treated as a true contextual allomorph, instead of as a portmanteau, there is no reason why an overt Asp should disrupt the conditioning of this allomorphy given spanning. More broadly, the use of spans is intended (at least in Merchant 2015) as a way of enabling non-local conditioning across the board; but the Greek intervention patterns suggest that non-local conditioning is only possible under a restricted set of circumstances. A spanning approach cannot easily capture the tight link we find between successful non-local conditioning and the the nullness of intervening heads; though the relevant forms are generated, the intervention patterns are arguably not explained, all things being equal. 
The obvious counterargument at this point may be that all things are not equal; that is, that some other facet of the mechanics of span insertion can account for intervention in a principled way. For this to be the case, some elaboration of how competition is adjudicated in spanning would be necessary. In particular, given overlapping spans eligible to be lexicalized (e.g. <Voice Asp T Agr > versus < T Agr > above), how does the insertion mechanism decide which one should be targeted for insertion? For (18), one possibility is that, because Asp has formed its own trivial span, it cannot act as part of the bigger $<$ Voice Asp T Agr $>$ span; and, because discontinuous spans are disallowed, the mechanism somehow defaults to the smaller $<\mathrm{T}$ Agr $>$ span. This solution would amount to positing that a given head can only be a member of a single span per derivation, and that spans are 'persistent' throughout cycles of insertion. Besides making reference to the notion 'head' which spanning is arguably meant to eschew for the purposes of insertion, this assumption is far from standard: for example, in the analysis of Greek root suppletion in Merchant $(2015 ; 289)$, Voice and Asp form a single span that conditions insertion at the root, but act as separate trivial spans when insertion targets each of them (see (20) below).

At a minimum, then, further elaboration of the mechanics of competition and insertion in spanning would be needed to enable a more extensive comparison of approaches here. To the extent that the Greek facts suggest a crucial role for both the adjacency of heads and their overtness/nullness, they seem better captured in a theory with these parameters.

Though the Greek facts are suggestive, they cannot be said to be conclusive. An important question concerns the status of non-local conditioning more broadly: spanning has been invoked in cases where head adjacency is ostensibly too restrictive. Conclusions drawn from such cases of apparent non-local allomorphy must be examined against patterns of intervention; this is an important general goal. In what follows, I offer an attempt at reconciliation of this kind for the specific case of Greek, arguing that a well-known pattern of root suppletion is not non-local.

5.2. On Greek RoOt SupPletion. In a remarkably careful paper, Merchant (2015) argues that root suppletion in Greek is non-local across an overt intervening head, and thus furnishes an argument in favor of spanning. A fragment of Merchant's analysis of the three strongly suppletive verbs of the language in Table 7 is in (19)-(20). The verbs in 7 arguably involve three root allomorphs; in the analysis in Merchant (2015), the perfective allomorphs in (19-a)-(19-b) demand access to Asp across the (potentially overt) Voice node. These facts are then taken to necessitate a spanning analysis whereby $<$ Voice Asp $>$ conditions root insertion, as schematized in (20).

\begin{tabular}{cccc}
\hline \hline IMPF & ACT.PFV & NONACT.PFV & Gloss \\
\hline tro- & $\mathrm{fa}(\mathrm{\gamma})-$ & fayo- & 'eat' \\
vlep- & ठ- & iðo- & 'see' \\
le( $(\mathrm{\gamma})-$ & $\mathrm{p}-$ & $\mathrm{le}(\mathrm{\gamma})-/$ ipo- & 'say' \\
\hline \hline
\end{tabular}

Table 7. Root shapes of the strongly suppletive verbs 'eat', 'see' and 'say'

(19) VIs for root suppletion (Merchant 2015; 278)

a. $\sqrt{\mathrm{EAT}} \leftrightarrow / \mathrm{fa}(\mathrm{\gamma}) / / \ldots\left[{ }^{+} \mathrm{ACT}\right]_{\text {Voice }}\left[{ }^{+} \mathrm{PFV}\right]_{A s p}$

b. $\sqrt{\mathrm{EAT}} \leftrightarrow /$ fayo//__ $[-\mathrm{ACT}]_{\text {Voice }}[+\mathrm{PFV}]_{\text {Asp }}$

c. $\sqrt{\mathrm{EAT}} \leftrightarrow /$ tro/ 


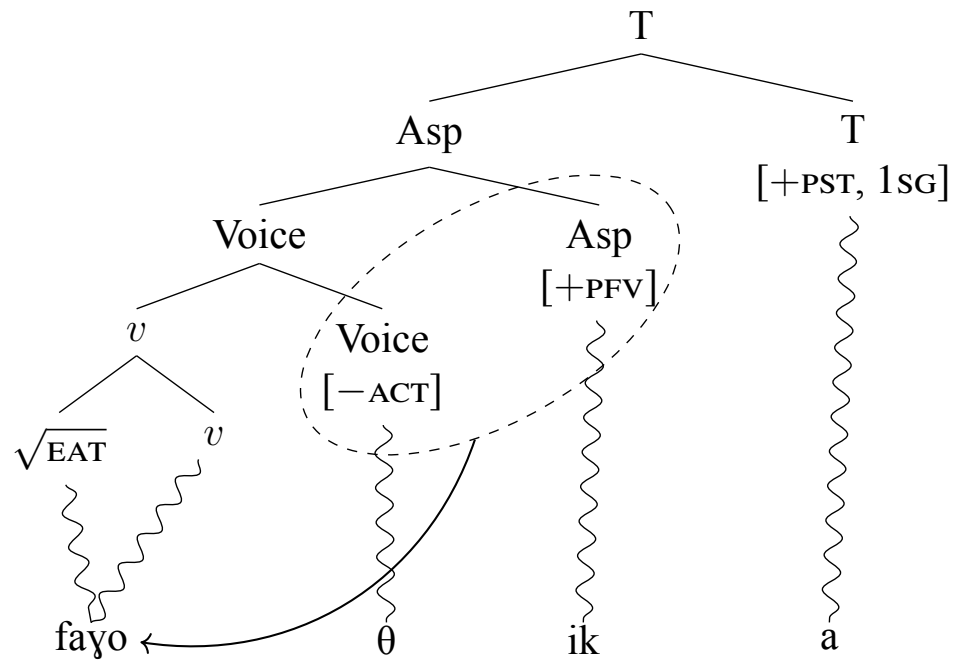

That this case of root suppletion is non-local rests on two assumptions. The first is the treatment of the affixes $-\theta$ and $-i k$ seen in (20). As argued in this paper, these exponents are in fact best treated as realizing Asp and T, respectively; taking $-\theta$ to be in Voice leaves its complementary distribution with the clearly aspectual $-s$ unexplained, and the same can be said for $-i k$ and the augment. Assuming the empirically more appropriate segmentation has an important consequence: Voice is null even when non-active, such that both (19-a) and (19-b) can now be made to comply with head adjacency via Pruning.

Perhaps more interestingly, the second (and tacit) assumption underlying non-locality in Merchant (2015) is that the elsewhere allomorph for the relevant verbs is the perfective one. This is in fact not the case: in all Greek suppletive verbs, it is the imperfective allomorph that is the default. This is evidenced by the fact that the imperfective allomorph (or one of the two imperfective allomorphs, if we follow Merchant) clearly has the wider distribution, as shown for $\sqrt{\text { EAT }}$ in (21): it is the one appearing in participles, root and event nominals, and root and verbal adjectives.
a. Participles (fayo-menos 'eaten', a-fayo-tos 'uneaten'); cf. *tro-menos, *tro-tos
b. Root nominals (faj-ito 'food'); cf. *tro-ito
c. Event nominals to fayo-ma/*tro-ma tis turtas apo ti Maria
the $\sqrt{\text { EAT }}-\mathrm{NMLZ}$ the.GEN cake.GEN by the Mary
'the eating of the cake by Mary'
d. Deverbal adjectives (fayo-sim-os 'edible'); cf. *tro-sim-os
e. $\quad$ Root adjectives ( $f a \gamma$-anos 'foodie', kalo-fay-as 'good eater'); cf. *tro-anos, *kalo-
tro- $a s$

The perfective allomorph tro- then appears only in perfective verbal forms; clearly, (19) makes the opposite prediction. Note that the same distribution holds for the other strongly suppletive verbs in Table 7, as well as for the language's many weakly suppletive verbs (if we follow Merchant in analyzing these as involving root allomorphy rather than morphophonological rules). In each case, the imperfective allomorph has the distribution of the default.

The appropriate Vocabulary for root suppletion must then be as in (22). The default root al- 
lomorph appears in the perfective, and suppletion targets the imperfective by (22-a); recall that, under any segmentation, both Asp and Voice are systematically null in the imperfective, thus no locality issue arises for a theory with head adjacency and Pruning. To the extent that we choose to recognize a separate root allomorph for the nonactive perfective (22-b), Pruning will apply here as well. It is, however, worth noting that, in all three verbs of Table 7, it is only the imperfective allomorph that is clearly phonologically dissimilar.

$$
\begin{array}{ll}
\text { a. } & \sqrt{\mathrm{EAT}} \leftrightarrow / \text { tro/ } / \\
\text { b. } & (\sqrt{\mathrm{EAT}} \leftrightarrow / \text { fayo/ } / \text {-PFV }]_{\text {Asp }} \\
\text { c. } & \sqrt{\mathrm{EAT}} \leftrightarrow / \text { fay } /
\end{array}
$$

This case of root suppletion is thus far from obviously non-local; despite appearances, Greek does not evidence a clear case of non-local suppletion across an overt head.

6. Conclusion. I have presented two case studies on morphological intervention from the Modern Greek verbal system. In both cases, the realization of a head may be conditioned at a distance, but only when all intervening heads are null; overt interveners cause the target of allomorphy to retreat to a default realization.

I have argued that these facts follow under an adjacency-based approach to the locality of allomorphy, one whereby apparently non-local conditioning is possible only across null nodes. Though the Greek facts do not clearly allow us to distinguish between linear and structural adjacency, they do not seem amenable to a less restrictive spanning-based approach. This conclusion leads to a re-examination of apparent evidence for spanning from the same language: upon closer examination, root suppletion in Greek is not non-local.

As in any domain of inquiry, arguing for or against different theories is a process that takes place at a level which includes, but is not limited to, consideration of individual case studies. How well the arguments here generalize depends to some extent on whether cases of intervention of the kind discussed here obtain more broadly. This question is left for a more systematic cross-linguistic discussion; here, I have tried to argue that advancing our understanding of the locality conditions on allomorphy requires focus not only on visibility, but also on intervention.

\section{References}

Adger, David, Susana Béjar \& Daniel Harbour. 2003. Directionality of allomorphy: A reply to Carstairs-McCarthy. Transactions of the Philological Society 101(1). 109-115. https://doi.org/10.1111/1467-968X.00111.

Allen, Margaret. 1979. Morphological investigations: Storrs, CT: University of Connecticut dissertation.

Bobaljik, Jonathan David. 2000. The ins and outs of contextual allomorphy. University of Maryland Working Papers in Linguistics 10. 35-71.

Bye, Patrik \& Peter Svenonius. 2012. Non-concatenative morphology as epiphenomenon. In Jochen Trommer (ed.), The morphology and phonology of exponence, 427-495. Oxford: Oxford University Press. https://doi.org/10.1093/acprof:oso/9780199573721.003.0013.

Embick, David. 1998. Voice systems and the syntax/morphology interface. In Heidi Harley (ed.), Proceedings of the Penn/MIT Workshop on Aspect, Argument Structure, and Events.

Cambridge, MA: MIT Working Papers in Linguistics.

Embick, David. 2010. Localism versus globalism in morphology and phonology. Cambridge, MA: MIT Press. 
Embick, David. 2012. Contextual conditions on stem alternations: Illustrations from the Spanish conjugation. In Irene Franco, Sara Lusini \& Andrés L. Saab (eds.), Romance languages and linguistic theory 2010: Selected papers from 'Going Romance' Leiden 2010, 21-40. Amsterdam: John Benjamins. https://doi.org/10.1075/rllt.4.02emb.

Galani, Alexandra. 2005. The morphosyntax of verbs in Modern Greek. York, UK: University of York dissertation.

Ganenkov, Dmitry. 2020. Missing elsewhere: Domain extension in contextual allomorphy. Linguistic Inquiry 51(4). 785-798. https://www.muse.jhu.edu/article/771865.

Halle, Morris \& Alec Marantz. 1993. Distributed Morphology and the pieces of inflection. In Ken Hale \& Samuel J. Keyser (eds.), The view from Building 20: Essays in linguistics in honour of Sylvain Bromberger, 111-176. Cambridge, MA: MIT Press.

Joseph, Brian D. \& Jane C. Smirniotopoulos. 1993. The morphosyntax of the Modern Greek verb as morphology and not syntax. Linguistic Inquiry 24(2). 388-398. https://www.jstor.org/stable/4178818.

Kaisse, Ellen M. 1982. On the preservation of stress in Modern Greek. Linguistics 20. 59-82. https://doi.org/10.1515/ling.1982.20.1-2.59.

Leu, Thomas. 2020. What do Greek verb stem allomorphy and Chichewa Mirror violations have in common? A phrasal movement analysis. Presented at Syntactic Approaches to Morphology Workshop. New York University.

Manzini, Rita, Anna Roussou \& Leonardo M. Savoia. 2016. Middle-passive voice in Albanian and Greek. Journal of Linguistics 52(1). 111-150. https://doi.org/10.1017/S0022226715000080.

Merchant, Jason. 2015. How much context is enough? Two cases of span-conditioned stem allomorphy. Linguistic Inquiry 46(2). 273-303. https://doi.org/10.1162/LING_a_00182.

Moskal, Beata \& Peter W. Smith. 2016. Towards a theory without adjacency: Hyper-contextual VIrules. Morphology 26(3-4). 295-312. https://doi.org/10.1007/s11525-015-9275-y.

Ostrove, Jason. 2018. Stretching, spanning, and linear adjacency in Vocabulary Insertion. Nat Lang Linguist Theory 36(4). 1263-1289. https://doi.org/10.1007/s11049-018-9399-y.

Pavlou, Natalia. 2017. Deriving the past tense augment. In Kate Bellamy, Anastasiia Ionova \& George Saad (eds.), Proceedings of ConSOLE XXV, 123-138. Leiden: Leiden University.

Petrosino, Roberto \& Christos Christopoulos. 2018. Greek root-allomorphy without spans. In Wm. G. Bennett, Lindsay Hracs \& Dennis Ryan Storoshenko (eds.), Proceedings of the 35th West Coast Conference on Formal Linguistics (WCCFL), 151-160. Sommerville, MA: Cascadilla.

Rivero, Maria-Luisa. 1990. The location of nonactive voice in Abanian and Modern Greek. Linguistic Inquiry 21(1). 135-146.

Siegel, Dorothy. 1978. The Adjacency Constraint and the theory of morphology. In Mark J. Stein (ed.), Proceedings of the Annual Meeting of the North Eastern Linguistics Society (NELS) 8, 189-197. Amherst, MA: GLSA.

Spyropoulos, Vassilios \& Anthi Revithiadou. 2009. The morphology of past in Greek. Studies in Greek Linguistics 29. 108-122.

Spyropoulos, Vassilios, Anthi Revithiadou \& Phoevos Panagiotidis. 2015. Verbalizers leave marks: Evidence from Greek. Morphology 25(3). 299-325. https://doi.org/10.1007/s11525-015-9260-5.

Svenonius, Peter. 2012. Spanning. Manuscript, University of Tromsø.

van Oostendorp, Marc. 2012. Stress as a proclitic in Modern Greek. Lingua 122(11). 1165-1181. https://doi.org/10.1016/j.lingua.2012.05.006. 